\title{
AS REDES SOCIAIS NA DIVULGAÇÃO E FORMAÇÃO DO SUJEITO DO CONHECIMENTO: COMPARTILHAMENTO E PRODUÇÃO ATRAVÉS DA CIRCULAÇÃO DE IDEIAS
}

\author{
Cristiane Dias* \\ Olivia Ferreira do Couto**
}

Resumo: As redes sociais são ambientes virtuais nos quais sujeitos se relacionam instituindo uma forma de sociabilidade que está ligada à divulgação e à própria formulação do conhecimento. A sociabilidade nas redes sociais, como o Orkut, o Facebook e o Twitter não têm as mesmas condições de produção que a sociabilidade em espaços escolares ou universitários, por exemplo, pois o imaginário que rege essas relações é diferente daquele que rege as relações nas redes sociais. Nas redes, esse imaginário diz. respeito a um modo de constituição do sujeito que passa pela formulação e circulação de um conbecimento do mundo, de um saber. É desse modo que as redes sociais serão, aqui, objeto de análise, a fim de compreendermos como, através delas, o sujeito do conbecimento se constitui à medida que dá visibilidade/formula/ divulga e produz conhecimento.

Palavras-chave: Discurso. Redes sociais. Divulgação. Circulação.

\section{INTRODUÇÃO E FUNDAMENTAÇÃO TEÓRICA}

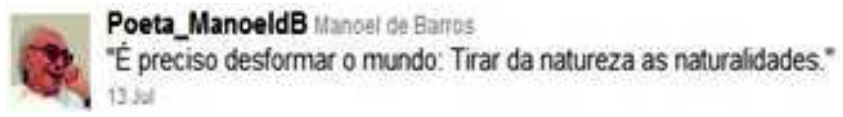

A questão central deste artigo é refletir sobre os efeitos de Redes Sociais da Internet na constituição do sujeito do conhecimento contemporâneo e verificar até que ponto a constituição do sujeito e a formulação do conhecimento científico e do mundo se atravessam no modo de circulação e divulgação desse conhecimento nas redes sociais.

Assim, nossa pergunta inicial é: de que sujeito do conhecimento estamos falando? Da perspectiva teórica da análise do discurso, que

\footnotetext{
* Pesquisadora do LABEURB/Nudecri/Unicamp. Doutora em Linguística. Email: crisdias@unicamp.br

** MDCC/IEL/LABJOR/Unicamp. Mestranda em Divulgação Científica e Cultural. Email: oliviafcouto@gmail.com
} 
considera a linguagem em sua materialidade, ou seja, em relação ao processo de produção da vida em sociedade, diremos que o sujeito do conhecimento é um sujeito histórico. Não é um sujeito abstrato, idealista, da "objetividade da verdade científica", aquele que tudo sabe. Não estamos falando da objetividade abstrata do saber nem da subjetividade idealista do sujeito, mas estamos, sim, falando de um sujeito que se constitui no confronto dos saberes, na contradição dos acontecimentos, no caso, o acontecimento das novas tecnologias digitais.

Em primeiro lugar, procurando situar o sujeito do conhecimento contemporâneo, afetado pelas tecnologias digitais, consideraremos:

\subsection{O POLÍTICO}

Paul Henry (1992), ao referir-se à objetividade e à verdade científica do conceito de luta de classes, afirma que esta "é uma objetividade e uma verdade prática, concreta, que visa a realidade não como substância ou uma coisa, fosse ela reduzida a uma estrutura puramente formal, mas enquanto processo material" (p. 127). Referindonos agora a outras condições de produção históricas do conhecimento e do sujeito, que não as da luta de classes, poderíamos situar a objetividade das novas tecnologias como aquela que visa a realidade enquanto processo material. Isso implica considerar a relação entre a forma-sujeito do político e a forma-sujeito do conhecimento científico (PÊCHEUX, 1995; HENRY, 1992). Formas essas, segundo Henry (1992, p. 128), separadas no campo da complementaridade da realidade psicológica e da realidade social, na neutralidade da Ciência. Tomamos como posto aqui, portanto, que o processo de produção do conhecimento é político. Ou seja, estamos falando de um sujeito determinado por um processo histórico. O que é, comumente, apagado quando se trata de novas tecnologias digitais e sua organização em rede. O que é preciso compreender é que há uma estreita relação entre o político (o governo), o conhecimento (a ciência) e a tecnologia (lugar de administração tanto do político quanto do conhecimento), conforme nos ensina Orlandi (2003). Tem-se a impressão (e trabalha-se no sentido de produzir esse efeito), contudo, de que o sujeito controla, domina e determina os 
caminhos da sociedade e da história, através de comandos de computador e de conexões em rede.

O que temos, na realidade, é um processo histórico e político mais amplo, que não se inicia com a popularização da Internet, mas com a globalização - implantação das redes mundiais de informação e comunicação. A popularização da internet, no entanto, é parte desse processo. E nele as redes sociais assumem papel preponderante no que diz respeito à divulgação do conhecimento e aos modos de subjetivação e individuação do sujeito.

No livro Como a web transforma o mundo: a alquimia das multidões, Pisani e Piotet $(2010$, p. 33) afirmam que o que os jovens realmente amam na internet são "as redes de relacionamento sociais e todas as suas ferramentas". Isso traduz uma ruptura de gerações, mas especialmente uma ruptura de usos. Nessa mesma perspectiva, Barbara Cassin (2008, p. 19-20) mostra que o uso dos diferentes instrumentos muda o sentido produzido para determinada tecnologia:

Gostaria de explicitar rapidamente o que representa a Net para alguém da minha geração, uma geração intermediária que não conheceu a tela e o teclado senão depois dos livros [...] Uma geração que também conheceu as cartas manuscritas, com grafologia instintiva e fórmulas de cortesia sociologicamente normalizadas, antes do correio eletrônico e seu "Bom dia" $[\ldots . .]^{1}$.

O fato é que, de um modo ou de outro, somos todos afetados por uma transformação social. Nesse sentido, apontamos um segundo aspecto que faz parte daquilo que consideramos as condições de produção históricas da noção de sujeito do conhecimento contemporâneo.

\footnotetext{
1 Tradução livre de: "Me gustaría explicitar rápidamente lo que representa la Net para alguien de mi generación, una generación intermediaria que no conoció la pantalla y el teclado sino después de los libros [...] Una generación que también conoció las cartas manuscritas, con grafología instintiva y fórmulas de cortesía sociológicamente normalizadas, antes del correo electrónico y su 'Buen día” (p. 19-20).
}

DIAS; COUTO - As redes sociais... 


\subsection{OS MODOS DE SUBJETIVAÇÃO E INDIVIDUAÇÃO}

Segundo Orlandi (2001), para compreendermos a subjetividade, é preciso tomar conhecimento de um duplo movimento que a constitui:

a) o de que quando o indivíduo entra no mundo da linguagem (no simbólico), os sentidos já têm sentido, a história já é movimento. Portanto, é preciso que esse indivíduo se assujeite à língua e à história para ser sujeito. O sujeito vai significar com sentidos já significados. A partir daí entra o segundo movimento:

b) a relação do sujeito com a linguagem é parte da relação do sujeito com o mundo. Assim, é pelo modo como esse sujeito irá se individuar na relação com as instituições (dentre elas as instituições de ensino) e os discursos, que ele assumirá na sociedade uma posição x, y ou z.

A partir desses dois momentos, perguntamos pelo modo como as instituições de ensino de modo geral formulam o conhecimento, as "coisas-a-saber" (PÊCHEUX, 2008), a partir das novas tecnologias digitais, de modo que a partir dessa formulação o sujeito assuma posições no mundo.

Por fim, um terceiro aspecto a ser considerado nessa abordagem do sujeito do conhecimento contemporâneo, afetado pelas tecnologias digitais e pelas mídias sociais: o discurso.

\subsection{O DISCURSO}

Para Pêcheux (2008), o discurso é efeito de sentidos entre locutores. Ele traz, assim, marcas da articulação da língua com a história para significar. Se pensarmos, então, no discurso das novas tecnologias digitais, veremos que ele se constitui pela filiação aos sentidos de inovação, avanço tecnológico, novo, inclusão, internet, redes sociais e outros. Todas essas questões são parte da produção de sentidos para tecnologias digitais. Para todos nós.

Assim, levando em consideração esses três aspectos constitutivos da relação que se estabelece entre tecnologia e educação, podemos pensar as tecnologias na educação, ou seja, o papel que elas 
exercem na aprendizagem e, portanto, na formação do sujeito do conhecimento contemporâneo através das mídias sociais.

Historicamente, a educação se constitui pelo formalismo. Com isso, um professor não deve ensinar seus alunos a pensar, desenvolver ideias, a compreender processos. Esse é um aspecto importante que justifica a dificuldade das instituições de ensino em compreenderem o modo de produção, formulação e circulação do conhecimento através das mídias sociais.

No entanto, não há como escapar da re-significação da concepção de ensino-aprendizagem com as mídias sociais, portanto, não há como escapar às formas de divulgação em (dis)curso que produzem sentidos a partir dessa re-significação. É preciso compreender, portanto, as mudanças e suas implicações para a forma-sujeito contemporânea, para as relações de poder (econômicas, sociais) que significam a divisão dos sentidos na produção de conhecimento.

Para não cairmos num formalismo renovado e tecnológico, produzindo fórmulas de aprendizagem com as mídias sociais, é preciso compreendermos o funcionamento dessas mídias no que diz respeito à produção e à circulação do conhecimento. Héctor Navarro Güere (2010) conta que

a universidade está sendo obrigada a mudar. Já se fala hoje de novos métodos de ensino, a open education. A informação não viaja mais em uma só direção, ela se constrói entre todos os alunos. A informação está na rede e o professor não é mais soberano. A experiência colaborativa 2.0 está cada vez mais presente. $\mathrm{O}$ modelo de um professor dogmático deve desaparecer. Um aluno inquieto e curioso tem acesso aos mesmos conteúdos que o professor. A escola será um canalizador de ideias e um orientador. Hoje, nas minhas aulas, é comum alunos contestarem o que estou mostrando, porque estão, muitas vezes, conectados à internet por meio de seus celulares e podem atualizar algumas informações que repasso a eles em tempo real. É um caminho sem volta. 
Compreender o funcionamento das mídias sociais na produção e circulação do conhecimento e na constituição do sujeito do conhecimento contemporâneo é compreender o político, ou seja, como mostra Orlandi (2001), o modo de subjetivação do sujeito numa determinada formação social.

Portanto, nossa questão aqui é compreender qual é o modo de subjetivação do sujeito contemporâneo em relação às novas formas de produção do conhecimento, na formação social das novas tecnologias de informação. Como esse sujeito se relaciona com as "coisas-a-saber" (PÊCHEUX, 2008) através das mídias sociais?

Nessa pergunta está embutida a estreita relação políticosubjetividade-discurso.

O político, segundo Orlandi (2010), "está no fato de que os sentidos são divididos, não são os mesmos para todo mundo, embora 'pareçam' os mesmos" (p. 12). Assim, perguntamos, qual é o sentido da tecnologia digital para o sujeito-usuário das redes sociais, de um lado, e para as instituições (Estado, Ensino e Pesquisa, Jornais), de outro lado, que regulam o saber e decidem o que pode e deve circular? Será que o conhecimento tem o mesmo sentido para as instituições e para o sujeito que o recorta, "linka", o coloca em relação com outras discursividades, o faz circular em meio a outros dizeres?

\section{AS REDES SOCIAIS}

As redes sociais são ambientes virtuais nos quais sujeitos se relacionam instituindo uma forma de sociabilidade que está ligada à própria formulação e circulação do conhecimento. A sociabilidade nas redes sociais, como o Orkut, Facebook e Twitter, não tem as mesmas condições de produção que a sociabilidade em espaços escolares ou universitários, por exemplo, e essa é uma diferença importante para compreender a divulgação de conhecimento em (dis)curso na sociedade contemporânea. A explicação para isso é a de que o imaginário que rege essas relações é diferente do imaginário que rege as relações nas redes sociais. Não esquecendo que imaginário é aquilo que "medeia a relação do sujeito com suas condições de existência" (ORLANDI, 1994, p. 56). 
Nas redes sociais, essa mediação do sujeito com as condições de existência que ele tem diante de si diz respeito ao modo de constituição desse sujeito nesse espaço. Esse modo de constituição passa, em nosso entender, pela formulação e circulação de um conhecimento do/no mundo, de um saber.

É desse modo que as redes sociais aqui em questão se organizam para constituir um sujeito do conhecimento e que, ao mesmo tempo, é produtor de conhecimento.

No caso do Facebook, isso ocorre pela possibilidade de colocar em circulação e compartilhar textos, artigos, vídeos, eventos, excertos, lançamentos de livros, campanhas, etc.. No Orkut, isso está ligado às comunidades às quais pertencem os usuários. E no Twitter, através do recurso de compartilhamento de links.

Assim, através da análise dessas redes sociais, nosso intuito é mostrar que as novas formas de aprendizagem devem considerar a constituição, formulação e circulação do saber, inseparavelmente, como momentos do "processo de produção do discurso" (ORLANDI, 2001, p. 9) de divulgação de conhecimento.

\section{ANÁLISE}

O que é preciso considerar, primeiramente, antes de entrarmos na análise do funcionamento e da constituição das redes sociais Orkut, Facebook e Twitter, na relação com o modo de produção, circulação do conhecimento, é que o que mobiliza o ingresso do sujeito nas redes sociais é a alteridade (o outro como constitutivo). Não há subjetividade sem alteridade, e a identidade resulta de uma identificação do sujeito. Assim, é dessa identificação do sujeito com o outro (memória, interdiscurso) que ele se subjetiva e se posiciona no mundo.

Vejamos, por exemplo, como isso ocorre no Orkut.

$\mathrm{O}$ perfil do sujeito-usuário do Orkut tem como entrada o enunciado "quem sou eu". Esse enunciado é um "convite" para que o sujeito fale de si mesmo. Com o que o sujeito se identifica? Quem é?

Se, no entanto, no Orkut, a entrada do sujeito é marcada pelo antigo questionamento filosófico: "quem sou eu", no Facebook, sua 
entrada é marcada pela pergunta/afirmação "fulano está lendo x" ou ainda "no que você está pensando agora?" e, no Twitter, a entrada é marcada pela pergunta "o que você está fazendo agora?"

Um dos aspectos a ser considerado nos enunciados que marcam a entrada do sujeito nessas redes sociais é que eles apontam para a volta do panóptico, o "tudo visto" que está no cerne das redes sociais citadas. O sujeito que não se diz nesse espaço, que não "cutuca", que não "curte", que não "comenta", que não "twitta" os acontecimentos passa a não existir nesse ciberespaço.

Segundo Foucault (2002, p.166, 167),

O dispositivo panóptico organiza unidades espaciais que permitem ver sem parar e reconhecer imediatamente. Em suma, o princípio da masmorra é invertido; ou antes, de suas três funções - trancar, privar de luz e esconder - só se conserva a primeira e suprimem-se as outras duas. A plena luz e o olhar de um vigia captam melhor que a sombra, que finalmente protegia. A visibilidade é uma armadilha.

[...] Uma sujeição real nasce mecanicamente de uma relação fictícia. De modo que não é necessário recorrer à força para obrigar o condenado ao bom comportamento, o louco à calma, o operário ao trabalho, o escolar à aplicação, o doente à observância das receitas.

O sujeito se constitui no dizer do que está fazendo a cada momento, o verbo "estar" transborda o ser. A formulação "o que estou fazendo agora" dá pistas de "quem sou eu", o modo de existir no digital é atravessado pelo estar visível ao outro.

Colocando em relação o modo de entrada do sujeito nessas redes sociais, temos a seguinte leitura:

\begin{tabular}{|l|l|l|}
\hline Sujeito & Rede social & Ordem discursiva \\
\hline QUEM SOU EU & ORKUT & ORDEM DO SER \\
& & \\
O QUE ESTÁ ACONTECENDO? & TWITTER & ORDEM DAS COISAS-A-SABER \\
O QUE VOCÊ ESTÁ PENSANDO? & FACEBOOK & \\
O QUE VOCÊ ESTÁ PLANEJANDO? & FACEBOOK & \\
\hline
\end{tabular}


$\begin{array}{ll}\text { Quem sou } & (\mathrm{eu}) \\ \text { O que está } & (\text { você })+\text { verbo }\end{array}$

A mudança de pergunta indica uma mudança no modo de constituição do sujeito, na ordem do discurso racional/liberal da ciência moderna para a ordem do discurso da ciência contemporânea.

Dante Gallian (2004), em artigo intitulado Ética, ciência e biologia, diz:

É incrível observar que no momento em que a ciência contemporânea parece atingir o seu mais alto grau de sofisticação técnica e especialização, ela parece querer se abrir - ou melhor, necessitar se abrir - para o universo de onde ela partiu mas do qual tanto se afastou: o universo das humanidades; o universo da filosofia, da história, da arte... [em que] o método científico se reencontraria com a reflexão, com a criatividade, com a poesia.

Ao deslizar "quem sou" para "o que está" coloca-se o foco da constituição no "outro" (aquilo que está fora, mas que é constitutivo do sujeito) e não no "eu" (o sujeito em sua essência). Aquilo que o sujeito conhece, sabe, é o que o define, o que constitui o seu ego-imaginário.

Ao questionar quem sou eu?, o sujeito passa necessariamente pela questão da origem e do sentido, para então relacionar-se consigo mesmo.

Ao questionar "o que você está pensando, fazendo, planejando", o que (eu sei que) está acontecendo (comigo?) no mundo e que me afeta enquanto sujeito, o sujeito busca o sentido do "quem sou eu". O recorte 1, de um perfil do Orkut, mostra o modo como se dá esse deslizamento de sentido do "quem sou" para "o que está": 


\section{RECORTE 1 - PERFIL}

"Um sentimento de impunidade caracteriza hoje o povo israelense e seu exército. Transformaram-se em rentistas do holocausto. Com todo respeito pelo povo assassinado, torturado e envenenado com gases.

"Os judeus que foram sacrificados nas câmaras de gás talvez se envergonhariam se tivéssemos tempo de lhes dizer como estão se portando os seus descendentes.

Não é possível pensar uma identidade senão no movimento da alteridade, não é possível pensar o eu sem pensar o outro que o constitui, não é possível pensar o mesmo sem pensar a diferença que o habita, não é possível pensar o tempo sem pensar as condições históricas que significam o sujeito, não é possível pensar o que somos sem pensar de onde viemos (o que nos constitui, nossas filiações), e para onde vamos (o que faremos, nossas escolhas), o que faz com que nos voltemos para nós mesmos, para re-significarmos, mediante a constituição de sentido, aquilo que nos constitui na nossa relação com o conhecimento do mundo e com o conhecimento científico.

Quem não vê nas mais diversas páginas da Internet o ícone do Facebook: "Curtir"? Basta clicar para que essa leitura, busca, acesso, seja imediatamente postado no "perfil" do sujeito no Facebook e passe a enunciar o que ele é ou o que está pensando, lendo. São as identificações do sujeito que vão constituindo-o na relação de alteridade e que vão dando pistas de sua posição no mundo. A identidade aqui definida não como algo fixo, mas como um movimento na história.

O falar de si constitui um movimento de alteridade, uma alteridade de diferença e uma alteridade de relação, conforme propõe Labarrière (1983). Uma vez que a alteridade de diferença vem a ser vivida como alteridade de relação, dá-se o movimento de liberdade, pois o sujeito formula, mediante a produção do sentido, o discurso que o constitui. 
Ao perguntar "o que você está pensando", pergunta-se pelo sentido. O sujeito é interpelado a falar de si, de sua subjetividade, do seu pensamento, das suas ideias sobre o mundo e os acontecimentos.

Podemos dizer que a pergunta "quem sou eu" é do sujeito para si mesmo, e "o que você está pensando" é do sujeito para o outro.

Seja num ou no outro movimento do dizer, o sujeito cria um lugar de enunciação de si, de busca pelo sentido de sua existência, o seu lugar na história. E esse movimento é a própria construção do conhecimento.

\section{RECORTE 2 - FACEBOOK}

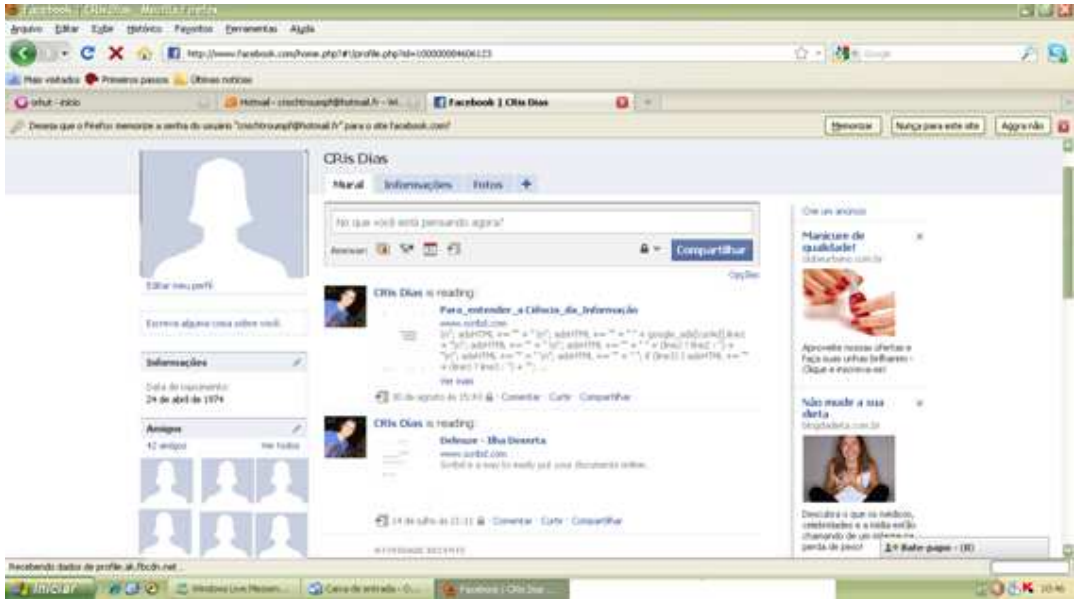

\section{RECORTE 3 - TWITTER}

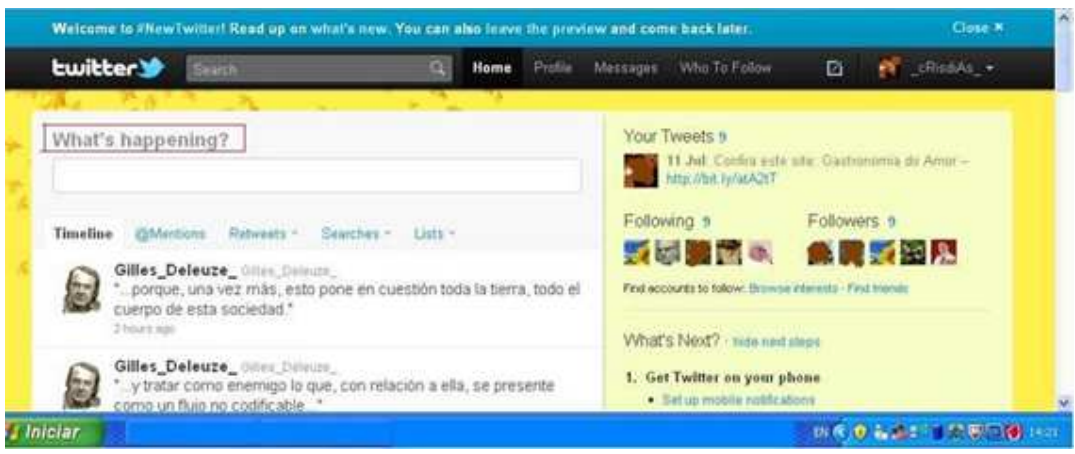

DIAS; COUTO - As redes sociais... 


\section{RECORTE 4 - ORKUT}

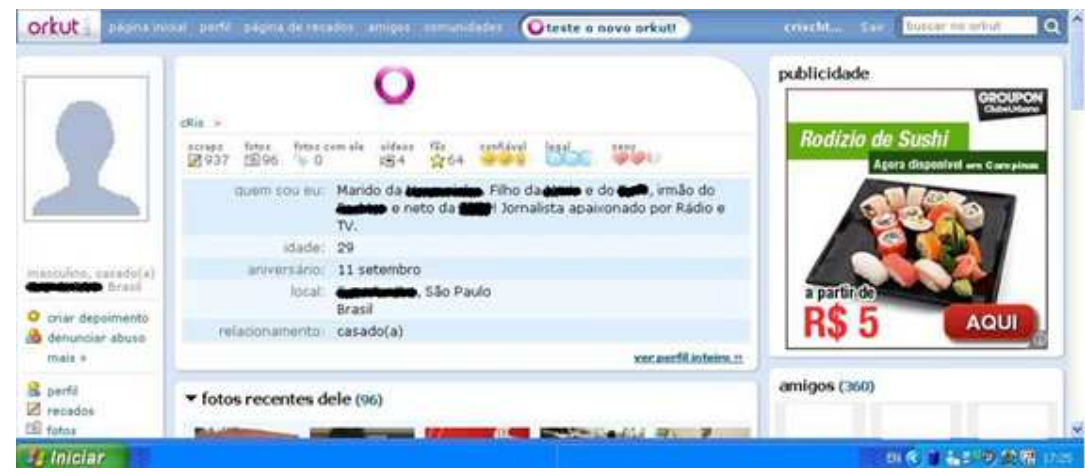

No recorte 4, de um perfil do Orkut, temos a formulação de um dizer sobre si, de uma "definição" do sujeito pela enumeração das filiações que constituem o "ser". Filiação familiar e profissional estão em pé de igualdade, na mesma ordem de sentido: Marido de $\mathrm{x}$, filho de $\mathrm{y}$, irmão de $z$, neto de h, jornalista...

No recorte 2, do Facebook, temos a formulação "o que você está pensando agora?", movimento de constituição do conhecimento (de si, do mundo, e científico), no qual o advérbio de tempo "agora" traz um tempo líquido, "esvaziado" de um passado, que escapa em sua fluidez.

Para Bauman (2007, p. 9),

Uma vida assim fragmentada estimula orientações "laterais", mais do que verticais. Cada passo seguinte deve ser uma resposta a um diferente conjunto de oportunidades e a uma diferente distribuição de vantagens, exigindo assim um conjunto de diferentes habilidades e um arranjo diferente de ativos. Sucessos passados não aumentam necessariamente as probabilidades de respostas futuras, muito menos as garantem, enquanto meios atestados com exaustão no passado precisam ser inspecionados e revistos, pois podem se mostrar inúteis ou claramente contraproducentes com a mudança de circunstâncias. Um imediato e profundo esquecimento de informações defasadas e o rápido envelhecimento de hábitos pode ser mais importante para o próximo sucesso do que a memorização de lances do passado e a construção de estratégias sobre um alicerce estabelecido pelo aprendizado prévio. 
Nesse sentido, a formulação temporal do conhecimento nas redes sociais se diferencia muito da formulação desse conhecimento na escola, por exemplo, que se baseia na memorização, na construção de um saber através da repetição, do decorar.

Gilles Lipovetsky (2004, p. 68) questiona sobre essas mudanças, nos fazendo repensar essa cronologia do tempo que, mesmo com as modificações, para o autor, ainda está calcada no futuro. "Embora triunfe o tempo breve da economia e da mídia, o fato é que nossas sociedades continuam voltadas para o futuro, menos romântico e paradoxalmente mais revolucionário, pois se dedicam a tornar tecnicamente possível o impossível." Para Lipovetsky (2004, p. 68), isso ocorre devido ao modo como a ciência se institucionaliza na sociedade atual:

Alcançou-se uma etapa nova na emancipação da tutela do elemento religioso: ápice da modernidade, essa etapa é sinônimo de hipermodernização da relação com o tempo histórico. Nada de ruína da força do futuro; essa última simplesmente não é mais ideológico-política, estando agora contida na dinâmica científica. Quanto mais a época se organiza num culto democrático erigido num absoluto de novo tipo, mais os laboratórios concebem o futuro dessemelhante e trabalham para construir um universo de ficção científica, até mais inacreditável que esta. A impotência para imaginar o futuro só aumenta em conjunto com a sobrepotência técnico-científica para transformar radicalmente o porvir: a febre da brevidade é apenas uma das facetas da civilização futurista hipermoderna. Enquanto o mercado estende sua "ditadura" do curto prazo, as preocupações relativas ao porvir planetário e aos riscos ambientais assumem posição primordial no debate coletivo [...] Se o eixo do presente é dominante, ele não é absoluto [...].

De que modo, então, esse tempo acelerado e redescoberto habita o espaço da escola formalista? 


\section{CONSTITUIÇÃO DO SUJEITO, FORMULAÇÃO E CIRCULAÇÃO DO CONHECIMENTO}

A questão que rege este artigo é: como é que o sujeito aprende e ao aprender se constitui em sujeito do conhecimento, da arte, da cultura?

No Facebook, as redes de relações que o sujeito estabelece com as “coisas-a-saber" são da ordem da dispersão. Basta abrir a página inicial para estar em relação com as coisas "do universo físico humano (coisas, seres vivos, pessoas, acontecimentos, processos...)" (PÊCHEUX, 2008, p. 29) em seu real constitutivo.

As instituições de ensino são espaços discursivos logicamente estabilizados, administrados, nos quais, através de regras, normas, técnicas materiais, supõe-se que o sujeito sabe do que se está falando, pois quem lhe fala está estabelecido como detentor do saber e responsável, segundo Pêcheux (2008), por diversas ordens. É esta ordem que as mídias sociais vão desestabilizar. É com esse sentido estabilizado do saber, da arte, da cultura, que elas vão mexer.

O fato é que o espaço escolar/universitário busca administrar esse real através de técnicas materiais que busquem "obter um resultado que tire partido da forma a mais eficaz possível dos processos naturais, para instrumentalizá-los, dirigi-los em direção aos efeitos procurados. Com isso, produz um espaço administrativo do saber, de gestão social dos indivíduos, diz Pêcheux (2008).

Isso resulta, do "ponto de vista técnico [...] numa separação entre ciência e saber" (ORLANDI, 2001, p. 158, grifos da autora). Falando a respeito da divulgação científica (DC), a autora diz que "lendo um artigo de DC você não conhece $x$, você sabe que $x$ ”.

Esse é o risco que corremos com o recobrimento da ciência, tecnologia e administração (ORLANDI, 2003). Com o mundo semanticamente normal que construímos, com os espaços discursivos unificados por uma série de evidências lógico-pragmáticas, marcados, hoje, pela multiplicidade de sistemas portáteis que "vão da gestão cotidiana da existência [(automóvel, celular, ipad, netbooks, etc.)] até as 'grandes decisões' da vida social e afetiva (eu decido fazer isto e não aquilo, de responder a $\mathrm{X}$ e não a $\mathrm{Y}$, etc....) passando por todo o contexto sócio-técnico dos 'aparelhos domésticos" (PÊCHEUX, 2008, p. 33). 
Não há como negar essa nossa necessidade. As coisas-a-saber "representam [...] tudo o que arrisca faltar à felicidade [...] do 'sujeito pragmático"' (p. 34). Daí nossa crença numa ciência régia, uma vez que as "coisas-a-saber" (informação?) estão extremamente interligadas com a ciência, produzindo uma "falsa-aparência da homogeneidade lógica encaixando a estabilidade discursiva própria às ciências da natureza, às técnicas materiais e aos procedimentos de gestão-controle administrativo [...]" (PÊCHEUX, 2008, p.41).

No entanto, se considerarmos o conhecimento a partir de um universo não-logicamente estável, podemos supor que há um outro tipo de saber que não se reduz à ordem das "coisas-a-saber", "um saber que não se transmite, não se aprende, não se ensina, e que, no entanto, existe, produzindo efeitos" (PÊCHEUX, 2008, p. 43).

Daí a proposta de novas práticas de leitura que colocam em relação aquilo que é dito de um modo (e não de outro) com o que é dito em outro lugar e de outro modo, a fim de colocar o sujeito em posição de "entender" a presença de não-ditos no interior do que é dito, distanciando-o, assim, da construção de uma ciência régia. Essa nova prática de leitura-aprendizagem pretende que as coisas-a-saber sejam "tomadas em redes de memória, dando lugar a filiações identificadoras e não a aprendizagens por interação: a transferência não é uma 'interação', e as filiações históricas nas quais se inscrevem os indivíduos não são 'máquinas de aprender"' (PÊCHEUX, 2008, p. 54).

Podemos observar esse deslocamento da constituição do conhecimento no Dicionário Digital de Lingua Portuguesa Priberam, por exemplo, que, ao mesmo tempo em que disponibiliza aos seus usuários o significado formal da palavra, também mostra os modos de sua utilização na rede social Twitter. No exemplo acima, digitamos a palavra 'educação' que, mesmo relacionada ao sentido gramatical, na linguagem em funcionamento ganha outras significações nas twittadas.

As redes sociais não são, portanto, máquinas de aprender, assim como as instituições de ensino não o devem ser, mas são espaços de identificação do sujeito, regidos por redes de memória não redutíveis a uma ciência régia. 


\section{RECORTE 5 - DICIONÁRIO PRIBERAM}

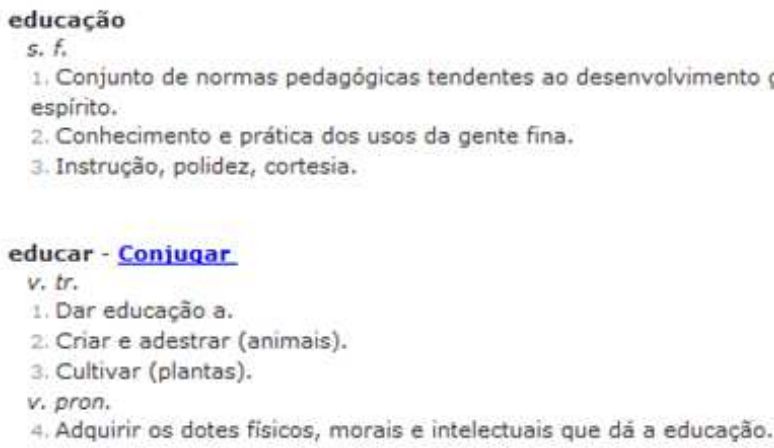

\begin{tabular}{|c|c|c|c|c|c|c|c|}
\hline Partilhar: & 5 Qurti & ir 1 & +1 & 0 & & * Tweetar & 0 \\
\hline Noticias & Blogues & Twitter & Relacionadas & & Estatisticas & & \\
\hline
\end{tabular}

Educaparo

Esta palavra no Twitter:

T. julyethsilveira - Cansei de tratar com educação quem merece ignorância. 20 minutes ago + reply + retweat + favorite

airtondefarias Sociedade cearense: precisamos de seu apoio. A legalidade está com os professores. RT as razđes da greve dos profs. http://t.co/VcGeygd 18 minutes ago + reply + retweet , favorite qihuwape A PROSPECTIVA NA EDUCAÇÃO: Enquanto as ciências $e$ as artes progridem e criam continuamente novidades para aten... http://bit.ly/n51TFJ

18 minutes ago - reply + retweet + favorite 


\section{REFERÊNCIAS}

BAUMAN, Z. Tempos líquidos. Tradução de Carlos A. Medeiros. Rio de Janeiro: Jorge Zahar, 2007.

CASSIN, B. Googléame: La segunda misión de los Estados Unidos. Buenos Aires: Fondo de Cultura Económica: Biblioteca Nacional, 2008.

FOUCAULT, M. Vigiar e punir: nascimento da prisão. Tradução de Raquel Ramalhete. Petrópolis, Vozes, 2002.

GALLIAN, D. M. C. Ética, ciência e biologia. Intervenção no Encontro Anual da Academia Brasileira de Ciências. 2004. Disponível em: <www.hottopos.com/videtur30/dante.htm> Acesso em: 1 dez. 2010.

GÜERE, H. N. Tecnologia para recriar os sentidos. Entrevista concedida ao caderno Informátic@ do jornal Estado de Minas. 2010. Disponível em: $<$ http://etcedigital.wordpress.com/2010/09/02/tecnologia-para-recriar-ossentidos/> Acesso em: 4 maio 2011.

HENRY, P. A ferramenta imperfeita: língua, sujeito e discurso. Tradução de Maria Fausta P. de Castro. Campinas: Editora da Unicamp, 1992.

LABARRIÈRE, P.-J. Le discours de l'altérité. Paris: PUF, 1983.

LIPOVETSKY, G. Os tempos hipermodernos. Tradução de Mário Vilela. São Paulo: Editora Barcarolla, 2004.

ORLANDI, E. Discurso e políticas públicas urbanas: a fabricação do consenso. Campinas: RG Editora, 2010. out. 2003.

Os recursos do futuro: um outro discurso. Revista Multiciência, n. 1, Discurso e texto: formulação e circulação dos sentidos. Campinas: Pontes, 2001.

Discurso, imaginário social e conhecimento. Em aberto, Brasília, Ano 14, n. 61, jan./mar. 1994.

PÊCHEUX, M. Semântica e discurso: uma crítica à afirmação do óbvio. Tradução de Eni Orlandi. Campinas: Editora da Unicamp, 1995.

O discurso: estrutura ou acontecimento. 5. ed. Tradução de Eni Orlandi. Campinas: Pontes, 2008. 
PISANI, F.; PIOTET, D. Como a web transforma o mundo: a alquimia das muldidões. Tradução de Gian Bruno Grosso. São Paulo: Editora Senac São Paulo, 2010.

PRIBERAM. Dicionário da Língua Portuguesa, 2010. Disponível em:

$<$ http://www.priberam.pt/dlpo/default.aspx?pal=Educa $\% \mathrm{C} 3 \% \mathrm{~A} 7 \% \mathrm{C} 3 \% \mathrm{~A} 3 \mathrm{o}$ >. Acesso em: 30 ago. 2011.

Recebido em 02/10/11. Aprovado em 13/12/11.

Title: The Social Networks in the dissemination and formation of the subject of knowledge: sharing and production through the circulation of ideas

Authors: Cristiane Dias; Olivia Ferreira do Couto

Abstract: Social networks are virtual environments in which subjects relate to each other by instituting a form of sociability connected to the dissemination and the very construction of knowledge. The sociability in social networks, such as Orkut, Facebook and Twitter does not have the same conditions of production that the sociability in students' spaces such as school or university, for example, because the imaginary that governs these relationships is different from the one that governs the relationships in social networks. In networks, this imaginary is related to a manner of subject's constitution that is passed by the formulation and circulation of a knowledge of the world. That is how the social networks will be discussed bere, as object of analysis, in order to understand how the subject of knowledge constitute bimself through social networks, as he gives visibility and express, disseminate and produces knowledge.

Key Words: Discourse. Social networks. Dissemination. Circulation.

Titulo: Las redes sociales em la divulgación y formación des sujeto del conocimiento: compartimiento y producción a través de la circulación de ideas

Autores: Cristiane Dias; Olivia Ferreira do Couto

Resumen: Las redes sociales son ambientes virtuales en los cuales sujetos se relacionan instituyendo una forma de sociabilidad que está ligada a la divulgación y a la propia formulación del conocimiento. La sociabilidad en las redes sociales, como Orkut, Facebook y Twitter no tienen las mismas condiciones de producción que la sociabilidad en espacios escolares o universitarios, por ejemplo, pues el imaginario que rige esas relaciones es diferente de aquel que rige las relaciones en las redes sociales. En las redes, ese imaginario dice respecto a un modo de constitución del sujeto que pasa por la formulación y circulación de un conocimiento del mundo, de un saber. Es de ese modo que las redes sociales serán aquí, objeto de análisis, a fin de que comprendamos como a través de ella el sujeto del conocimiento se constituye a medida que da visibilidad/formula/ divulga y produce conocimiento.

Palabras-clave: Discurso. Redes sociales. Divulgación. Circulación.

Linguagem em (Dis)curso, Tubarão, SC, v. 11, n. 3, p. 631-648, set./dez. 2011 